
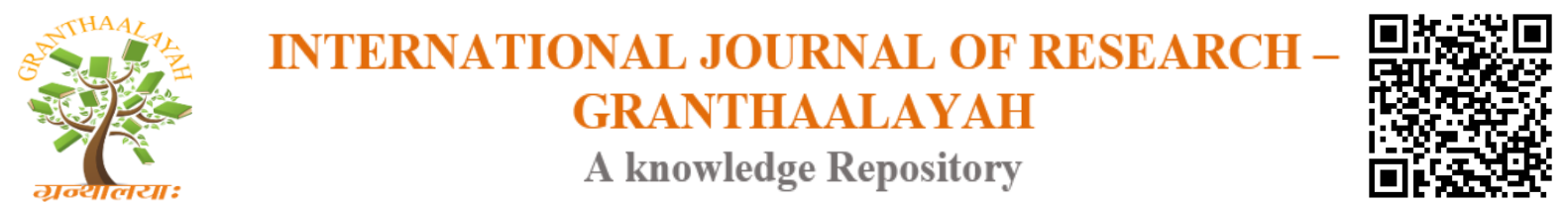

Social

\title{
THE EFFECT OF RECREATIONAL ACTIVITIES ON TRAIT AND STATE ANXIETY LEVELS
}

\author{
Güçï Özen *1 \\ *1 Department of Sport Management, Abant İzzet Baysal Univercity, Turkey
}

\begin{abstract}
Recreation is a concept referring to the activities people do in their spare time and how university students recreate their spare time completely takes place within the scope of facilities offered by the university.

Anxiety is a multifaceted inner feature that consists physiological, physiological and behavioral reactions or event. It can also be accepted as a broad concept for many complex, emotional and encouraging (motivating) situations that occurs as a result of any threat.

Research has been designed in a single group pre-test and post-test model. Research sample is same with study area which covers totally 180 of our university students (120 male and 60 female). Anxiety Inventory has been used as a measurement tool which was developed by Spielberger et al. (1970) and adapted by Öner and Le Compte (1995).

The purpose of this study is to determine the effect of recreational activities (trekking, camping, rock climbing) participated by the students on their anxiety level. As a result of the analysis; it was determined that the activities such as trekking, camping and rock climbing do not have a significant effect on trait anxiety scores of the participants, however; camping and rock climbing cause a significant increase on state anxiety scores. In terms of the gender variable, it has been found out that camping and rock climbing lead a statistically significant increase on state anxiety scores of female participants.

Consequently, it is possible to say that activities taking place in an unfamiliar environment with a high risk potential increase the state anxiety of participants and these physical activities have a higher level of influence on females in terms of state anxiety level.
\end{abstract}

Keywords: Recreational Activities; State Anxiety; Trait Anxiety; Camping Event; Climbing Event.

Cite This Article: Güçlü Özen. (2017). “THE EFFECT OF RECREATIONAL ACTIVITIES ON TRAIT AND STATE ANXIETY LEVELS." International Journal of Research - Granthaalayah, 5(12), 45-52. https://doi.org/10.29121/granthaalayah.v5.i12.2017.472.

\section{Introduction}

Relationship between anxiety and performance in sports psychology has always been a focus. Many researches have explained the relationship between anxiety and performance and it is said 
that very high level of anxiety negatively affects performance. Anshel et al. (1991) defined anxiety as the feeling of subjective tension that comes along with increased physiological arousal with the perception of threat (cited in Cağlar, 1999).

Anxiety is a reaction that one displays under emotional or physical pressure. In daily life, anxiety often describes a situation expressed with terms of fear, concern, and restlessness. Anxiety is a horror-like situation, however; it differs from fear in terms of uncertainty, severity and duration of the problem or source. In children's sports, stress and anxiety have very important physical and behavioral consequences. Trait Anxiety emerges as a very important factor among stress resources. Understanding the trait anxiety is quite important for children at risk especially in competition duties to be able to cope with stress (Gould, Udry, Tuffey and Loehr, 1996).

Anxiety can be regarded as one of man's basic feelings. We all have a little bit of anxiety in situations we see dangerous. This kind of anxiety caused by dangerous conditions creates a temporary, contextual anxiety generally experienced by each individual. This is called "state anxiety". In state anxiety, once the moment that creates tension and anxiety in the individual ceases, negative emotions also ceases (Batumlu, Erden; 2007).

Trait anxiety is the individual's closeness to anxiety. This can also be called the tendency of the individual to perceive situations usually stressed or to interpret them as stress. According to objective criteria, trait anxiety can be defined as the sense of dissatisfaction and unhappiness emerged due to the perception of neutral situations as dangerous and degrading by the individual. It is seen that individuals with such a high level of anxiety are easily hurt and become pessimistic. Trait anxiety is a feature that distinguishes individuals from each other (Öner, Le Compte, 1998).

Kir (2007) has pointed to the role of leisure in personal development of the individuals as well as in ensuring social prosperity and development, and then indicated that the habit of university students while using their leisure time passively is quite far from contributing to the prosperity of the country. In their study on understanding and habits of using leisure time of university students, Terzioglu and Yazic1 (2003) have stated that students have too much free time but they don't use it efficiently; all students think leisure time and sport as a means of physical and mental development.

In their study, Ardahan and Lapa (2011) have indicated that individuals participate in outdoor recreational activities in order to integrate nature, to influence their health positively, to get rid of troubles and stress, to get rid of monotony, to relax, to increase work efficiency, to be with friends, to acquire and use new skills, to get into a new circle, to get rid of loneliness etc.

In this respect, it is of great importance to have university students do and participate in various activities through communities. This type of activities need to be used to reach the students who cannot find a way on how and where to evaluate their leisure time through the communities led by those students again and need to be used as a contributing factor to personal development beside formal training. 


\section{Materials and Methods}

Research sample is same with study area which covers totally 180 of our university students (120 male and 60 female), who are the candidate member of Mountain Climbing and Rock Climbing community during the study period of 2013-2014 and actively participated in the activities (trekking, camping, climbing). During a whole semester, students have participated in activities of the community such as trekking, camping and rock climbing.

Study group attended three separate events in fifteen days apart and before the activities they filled a questionnaire without verbal and visual information about the event. The second data collection was performed during the event. In the study, State-Trait Anxiety Inventory (STAI) has been used as a data collection tool which was developed by Spielberger et al. (1970) and adapted by Öner and Le Compte (1995). In the reliability study conducted by Öner and Le Compte, Alpha reliability coefficient of State-Trait Anxiety Inventory was found between 0, 830, 87 in various applications for Trait Anxiety Scale and between 0,94-0,96 for State Anxiety Scale. Again in various applications, test-retest reliability was found between 0, 71-0, 86 for Trait Anxiety Scale and between 0,26-0,68 for State Anxiety Scale. Among the data obtained in our study, Alpha reliability coefficient of Trait Anxiety Scale is 0,88 whereas it is 0,79 for StateTrait Anxiety Inventory.

According to normality test in the study, independent t-test in independent groups and dependent $\mathrm{t}$-test in dependent groups have been used. SPSS statistical package program was used in order to evaluate the data and to find out the calculated values

\section{Results and Discussions}

Table 1 covers Dependent t-test results done for comparing pretest-posttest total scores of StateTrait Anxiety Scale for walking activity.

Table 1: Comparing pretest-posttest total scores of State-Trait Anxiety Scale for walking activity

\begin{tabular}{cccc}
\hline \multirow{2}{*}{ Walking } & Pre- test & Post- test & $\mathrm{t}$ \\
& $\mathrm{n}: 60$ & $\mathrm{nO}: 60$ & \\
\hline Trait & $42.81 \pm 6.54$ & $\mathrm{AO} \pm \mathrm{SS}$ & 0.89 \\
State & $34.99 \pm 7.26$ & $32.99 \pm 5.18$ & 1.02 \\
\hline
\end{tabular}

$* \mathrm{p}<0.05$

Once pre-test-post-test scores are examined in terms of walking activity, there was no statistically significant difference between trait and state anxiety scores $(p>0,05)$.

In terms of gender variable, Independent t-test was used to see the difference between the scores of pretest-posttest and difference in differences for walking activity and the results are given in Table 2. 
Table 2: Independent t-test in order to evaluate state and trait anxiety scale scores in terms of gender variable for walking activity $\mathrm{u}$

\begin{tabular}{|c|c|c|c|c|c|c|}
\hline \multirow{2}{*}{\multicolumn{2}{|c|}{ Walking }} & \multicolumn{2}{|c|}{ Pretest } & \multicolumn{2}{|c|}{ Posttest } & \multirow[t]{2}{*}{ Difference } \\
\hline & & $\begin{array}{l}\text { Male } \\
\text { n: } 40\end{array}$ & $\begin{array}{c}\text { Female } \\
\text { n: } 20\end{array}$ & $\begin{array}{l}\text { Male } \\
\text { n: } 40\end{array}$ & $\begin{array}{c}\text { Female } \\
\text { n: } 20\end{array}$ & \\
\hline Trait & $\underset{t}{\mathrm{AO} \pm \mathrm{SS}}$ & $\begin{array}{r}41.76 \pm 7.51 \\
0\end{array}$ & $\begin{array}{l}43.01 \pm 6.61 \\
6\end{array}$ & $34.99 \pm 7.41$ & $\begin{array}{l}36.75 \pm 5.89 \\
6\end{array}$ & .59 \\
\hline State & $\underset{t}{\mathrm{AO} \pm \mathrm{SS}}$ & $34.41 \pm 7.95$ & $3^{35.12 \pm 7.18}$ & $\begin{array}{r}35.99 \pm 6.72 \\
1\end{array}$ & $\begin{array}{l}36.75 \pm 6.19 \\
6\end{array}$ & .19 \\
\hline
\end{tabular}

Once considered the walking activity in terms of gender variable, there was no statistically significant difference found between the scores of pretest-posttest and difference in differences $(\mathrm{p}>0,05)$.

For camping activity, Dependent t-test results done for comparing the total scores of State-Trait Anxiety Scale pretest-posttest are given in Table 3.

Table 3: Comparing scores of State-Trait Anxiety Scale pretest-posttest

\begin{tabular}{cccc}
\hline Camping & $\begin{array}{c}\text { Pretest } \\
\mathrm{n}: 60\end{array}$ & $\begin{array}{c}\text { Posttest } \\
\mathrm{n}: 60\end{array}$ & $\mathrm{t}$ \\
& $\mathrm{AO} \pm \mathrm{SS}$ & $\mathrm{AO} \pm \mathrm{SS}$ & \\
\hline Trait & $41.55 \pm 6.76$ & $42.01 \pm 4.65$ & 0.75 \\
State & $37.59 \pm 7.26$ & $38.72 \pm 6.42$ & $1.98^{*}$ \\
\hline
\end{tabular}

$* \mathrm{P}<0.05$

Once pretest-posttest scores are examined in terms of the camping activity, there was no statistically significant difference found between trait anxiety scores $(p>0,05)$; however, a statistically significant difference was identified between state anxiety scores $(p>0,05)$.

In terms of gender variable, Independent t-test was used to examine the difference between pretest-posttest and the scores of difference of differences. Results are given in Table 4.

Table 4: Dependent t-test results in order to evaluate State-Trait Anxiety Scale Scores in terms of gender variable in camping activity

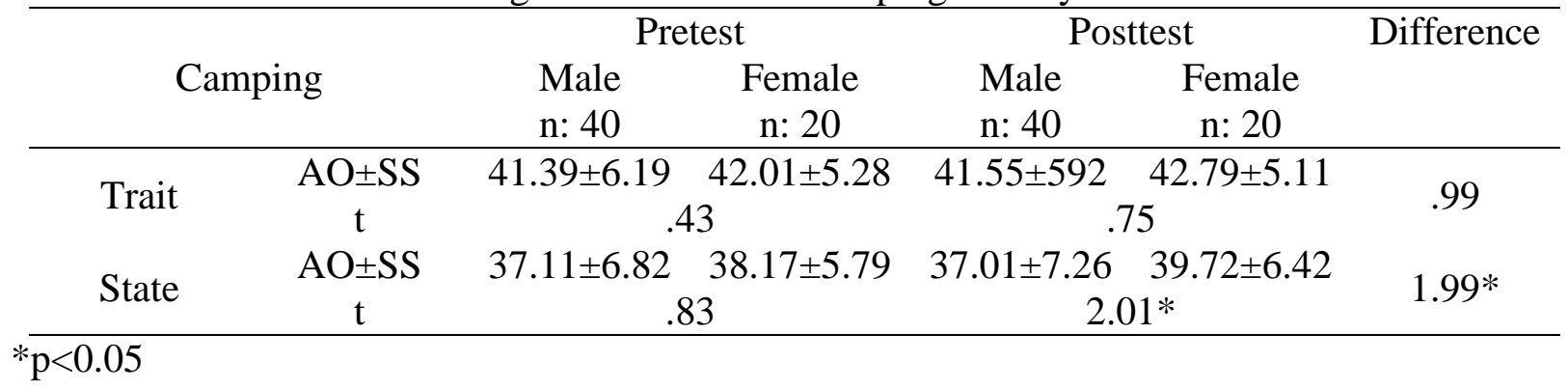

Considering the camping activity, there was no statistically significant difference found between the scores of pretest-posttest and difference of differences for trait anxiety scores in terms of 
gender variable $(p>0,05)$. In terms of state anxiety scores, no statistically significant difference was identified between pretest scores $(\mathrm{p}>0,05)$; however, a statistically significant difference was found between the scores of posttest and difference of differences $(p<0,05)$.

For rock climbing activity, Dependent t-test results for comparing the pretest-posttest total scores of State and Trait Anxiety Scale are given in Table 5.

Table 5: Comparison Table for the pretest-posttest scores of State and Trait Anxiety Scale in rock climbing activity

\begin{tabular}{cccc}
\hline Rock & Pretest & Posttest & $\mathrm{t}$ \\
Climbing & $\mathrm{n}: 60$ & $\mathrm{n}: 60$ & \\
& $\mathrm{AO} \pm \mathrm{SS}$ & $\mathrm{AO} \pm \mathrm{SS}$ & 0.89 \\
& $41.85 \pm 6.76$ & $42.96 \pm 5.52$ & $2.25^{*}$ \\
\hline Trait & $38.01 \pm 7.26$ & $40.98 \pm 6.12$ & \\
State &
\end{tabular}

$* \mathrm{p}<0.05$

Once pretest-posttest scores have been examined in terms of rock climbing activity, there was no statistically significant difference found between trait anxiety scores $(p>0,05)$; however, a statistically important difference was identified between state anxiety scores $(p<0,05)$.

In terms of gender variable, Independent t-test was used to examine the difference between the scores of rock climbing activity pretest-posttest and the difference of differences. Results are given in Table 6.

Table 6: Independent t-test table in order to examine State and Trait Anxiety Scale Scores in terms of gender variable in rock climbing activity

\begin{tabular}{|c|c|c|c|c|c|c|}
\hline \multirow{2}{*}{\multicolumn{2}{|c|}{ Rock Climbing }} & \multicolumn{2}{|c|}{ Pretest } & \multicolumn{2}{|c|}{ Posttest } & \multirow[t]{2}{*}{ Difference } \\
\hline & & $\begin{array}{l}\text { Male } \\
\text { n: } 40\end{array}$ & $\begin{array}{c}\text { Female } \\
\text { n: } 20\end{array}$ & $\begin{array}{l}\text { Male } \\
\text { n: } 40\end{array}$ & $\begin{array}{c}\text { Female } \\
\text { n: } 20\end{array}$ & \\
\hline Trait & $\underset{t}{\mathrm{AO} \pm \mathrm{SS}}$ & $41.41 \pm 6.11$ & $42.18 \pm 7.12$ & $41.85 \pm 6.76$ & $\begin{array}{l}42.96 \pm 5.52 \\
8\end{array}$ & .71 \\
\hline State & $\underset{t}{\mathrm{AO} \pm \mathrm{SS}}$ & $\begin{array}{r}37.45 \pm 6.58 \\
1\end{array}$ & $\begin{array}{l}41.98 \pm 7.95 \\
8\end{array}$ & $\begin{array}{r}39.27 \pm 5.95 \\
2 .\end{array}$ & $\begin{array}{l}42.18 \pm 6.72 \\
1^{*}\end{array}$ & $2.25^{*}$ \\
\hline
\end{tabular}

$* p<0.05$

Considering rock climbing activity, there was no statistically significant difference found between the scores of pretest-posttest and difference of differences for trait anxiety scores in terms of gender variable $(\mathrm{p}>0,05)$. In terms of state anxiety scores, no statistically significant difference was identified between pretest scores ( $p>0,05)$; however, a statistically significant difference was found between the scores of posttest and difference of differences $(p<0,05)$.

It is stated that development and learning is the result of a life (Selcuk, 2000), different life experiences create opportunities for the emergence of leadership skills of participants (Ozen and Vatansever, 2017) and an individual increase the awareness of both himself/herself and others by observing his/her real behaviors (Bank, 1994). It is desired to create changes in the anxiety level of participants with recreational activities in nature. Horney has made a distinction between fear 
and anxiety by saying that fear emerges in case of a real danger whereas anxiety is a feeling that emerges in case of a situation perceived as dangerous (cited in Yanbast1, 1996). From this point of view, there is no real threat found in the activities done, so participants can experience personal development by getting out of their comfort area with the perceived risk factor (Luckner and Nadler, 1997). Various studies revealed that activities done in nature offer psychological benefits through direct and active interaction. For instance, it is stated that outdoor training programs improve various personal and social outcomes (Maller et al. 2005; Ho, 2014; Clarke and Mchhie, 2014; Ozen and Vatansever, 2016). It is also suggested that the main factor why the whole event is a catalyst in personal development is the individual's getting out of his/her comfort zone (Kenzie, 2000).

The question asked in the last fifty years is whether or not a change occurs in participants after adventure training based on challenge and experiential learning method. Within the framework of recreational activities in which participants come together with different expectations, it has been emphasized that reciprocity leisurely developed in the group has a significant effect on personal development of group members (Hopkins and Putnam, 1993). It has been stated that entering a new social circle, getting rid of trouble, participants' getting out of comfort zones through various activities and facing with new situations lead to their personal development (Ozen, 2015). Increased situational anxiety of participants is an indicator that they are getting out of their comfort zone during the event. Especially the extraordinary activities such as camping and climbing which support us to explore our self-awareness and boundaries are mostly considered physically challenging ones but in fact these are the ones that help us to break our mental obstacles. In literature, it is emphasized that extraordinary climbing activity has significantly increased the anxiety level (Gürer et al., 2007; Ozen and Vatansever, 2016)

In literature, it is suggested that considering the participation of adventure-based events, there is a difference in participants' internal perception due to gender difference and once male participants succeed in something, this is due to their abilities; however, once female participants succeed in something, this is due to their luck or a special endeavor. As a result of this, it is asserted that women are mostly in search of spiritual development whereas men are in search of adventure (cited in Kenzie, 2000). In our study, it is considered that higher anxiety level of female participants in body power-based activities such as camping and climbing derives from a similar situation.

\section{Conclusions and Recommendations}

According to the results of the study above;

- Walking activity has no significant effect trait and state anxiety scores of participants,

- Camping activity has no significant effect on trait anxiety scores of the participants whereas it has significantly increased state anxiety scores,

- Rock climbing activity has no significant effect on trait anxiety scores of the participants whereas it has significantly increased state anxiety scores,

- Considering the independent gender variable, the following facts have been identified:

- For walking activity, there is no significant difference between the trait \& state anxiety pretest-posttest scores and the difference of differences scores, 
- In camping activity, there is no significant difference between the trait anxiety pretestposttest scores and the difference of differences scores; however, there is a significant difference between state anxiety posttest and difference of differences scores, which derives from the fact that females are more anxious.

- In rock climbing activity, there is no significant difference found between trait anxiety pretest-posttest and difference of differences scores; however, there is a significant difference between state anxiety posttest and difference of differences scores, which derives from the fact that females are more anxious.

With these results; it is possible to say that walking activity does not affect the anxiety level; camping and climbing activity increase the participants' state anxiety levels; camping and climbing activity lead a more significant increase on females' state anxiety levels.

\section{Suggestions}

Higher education programs need to offer different opportunities to students by considering the fact that current competence of an individual may not only be a result of the individual's ability and effort; it may be affected by socio-economic and cultural opportunities that the individual's has (Ekinci, 2011).

It is considered that the only way for students to recognize themselves, their boundaries and others, to create mental flexibility through various activities is different life styles. Additionally, it is possible to say that once the participant faces with an extraordinary activity in adventurebased trainings arranged for personal development, it will be helpful for them to get out of their comfort zone considering the anxiety scores received.

\section{Acknowledgements}

This study was supported by decision of BAP committee dated as 07.01.2014 and numbered 2014-62.

\section{References}

[1] Ardahan, F., Lapa T.Y. (2011). Outdoor Recreation: The Reasons And Carried Benefits For Attending Outdoor Sports Of The Participants Of Cycling And/Or Trekking Activities. International Journal Of Human Sciences 8 (1): 1327-1341

[2] Bank, J. (1994). Outdoor Development For Managers, 2nd Edn.Gower Publishing Company, Aldershot.

[3] Batumlu, D.Z. Ve Erden, M. (2007) The Relationship Between Foreign Language Anxiety And English Achievement Of Yıldız Technical University School Of Forreign Languages Preparatoryt Students. Journal Of Theory And Practice İn Education, 3(1): 24-38

[4] Clarke D. \& Mcphie J (2014) Becoming Animate İn Education: İmmanent Materiality And Outdoor Learning For Sustainability, Journal Of Adventure Education And Outdoor Learning, 14(3): 198-216

[5] Çağlar, E. Temporal Changes Of Anxıety Levels Of The Youth Andjunır Male Handball Natıonal Team Players. Hacettepe Journal Of Sport Sciences, 1999; 3(3): 19-28

[6] Ekinci, C. E, (2011) Impact Of Some Socio-Economic Factors On Higher Education Participation İn Turkey, Education And Science, 36 (160), 281-297 
[7] Gould, D., Udry, E., Tuffey, S. Ve Lochr, J. (1996). Burnout İn Competitive Junior Tennis Players: A Qualitative Psychological Assesment. The Sport Psychologist, 10, 322-340

[8] Gürer B. , Savaş Ha. , Gergerlioğlu Hs., Hazar Ch. , Uzun M., Savaş E. (2007) The Effect Of Altitude On Anxiety Level During Climbing Mount Süphan General Medicine Journals;17(3): 161-166

[9] Ho S. (2014) The Purposes Outdoor Education Does, Could And Should Serve İn Singapore, Journal Of Adventure Education And Outdoor Learning, 14 (2): 153-171

[10] Hopkins, D., Putnam, R. (1993). Personal Growth Through Adventure. London: David Fulton

[11] Kenzie, M. (2000). "How Are Adventure Education Program Outcomes Achieved?: A Review Of The Literature", Australian Journal Of Outdoor Education, 5 (1): 19-28

[12] Kır, İ. (2007). Leisure Activities Of Higher Education Youth: Ksü Example. Frrat University Journal Of Social Science, 17 (2): 307-328

[13] Luckner, J.L., Nadler, R.S. (1997), Processing The Experience: Strategies To Enhance And Generalize Learning. Dubuque, La: Kendal Hunt Publishing Company

[14] Maller, C., Townsend, M., Pryor, A., Brown, P., \& St Leger, L. (2005). Healthy Nature Healthy People: 'Contact With Nature' As An Upstream Health Promotion İntervention For Populations. Health Promotion International, 21(1), 45-54.

[15] Öner, N., Lecompte A. (1985, 1998) State-Trait Anxiety Inventory Manual. Second Edition. Boğaziçi University Publications, Turkey.

[16] Özen G. (2015). The Effect Of Climbing Community Activities As A Leisure On University Students' Social Anxiety. The Anthropologist, 21(3), 558-564.,

[17] Özen G., Vatansever S. (2016). Effect Of High Altitude Climbing On Anxiety Level. International Journal Of Social Sciences And Education Research, 2 (3), 1388-1398

[18] Özen G., Vatansever S. (2017). Examining The Effect of Artificial Wall Climbing as a Leisure Time Activity on Undergraduate's Problem-Solving Skills. International Journal Of Social Sciences And Education Research, 3(1), 39-48

[19] Selçuk, Z. (2000). Development and Learning, Nobel Publications. 7. Edition. Ankara.

[20] Şirin, A., Kavak, O., Ertem , G. (2003). Determination Of The State-Trait Anxiety Levels Of Students Who Are On Labour Room İn Maternity Hospital, C. Ü. Journal Of Nursing School, 7 (1): 27-32

[21] Terzioğlu, A. Ve Yazıcı, M. (2003). Graduate Student's Perception and Use of Leisure Time (Atatürk University Example), Erzincan University Journal Of Education Faculty, 5(2), 1-31.

[22] Yanbast1, G. (1996). Theories Of Personality. I1. Edition. İzmir. Press At Ege University

\footnotetext{
*Corresponding author.

E-mail address: guclu1234@ yahoo.com
} 